\title{
Prevalence of Uterine Prolapse and its Associated Factors in Kaski District of Nepal
}

\author{
${ }^{1}$ AnupamaTamrakar \\ ${ }^{1}$ School of Health and Allied Sciences, Pokhara University, Lekhnath, Kaski, Nepal
}

\begin{abstract}
Uterine Prolapse is widespread across the country and has affected women in the mountains, hills, plains and the valleys of Nepal. Uterine Prolapse is a condition when the uterus drops from its normal position in the pelvic cavity, descending into and eventually, in extreme stages, out of the vagina. The major purpose of the study was to assess the prevalence and factors associated with Uterine Prolapse in Kaski district of Nepal. A community based descriptive cross sectional study was conducted among 300 women of the Kaski district who have experienced at least one time pregnancy during her life. Multi-stage sampling technique was adopted. Face to face interview was conducted with respondents using pre-tested, semi structured interview schedule. Data were analyzed by using statistical package for Social Sciences 16 version. Prevalence of uterine prolapse was $11.7 \%$. Median duration of suffering was two years. Majorities of the respondents were over 30 year's age. Feeling of something coming down was reported by more than $42 \%$ cases followed by vaginal bleeding by more than $37 \%$ were seen as major symptoms. The strongest variation was observed in age of respondents, age at first child birth and smoking in the past and present. More than $50 \%$ had received treatment of uterine prolapse and most of them received services from hospitals followed by private medicals. More than $72 \%$ were treated by the application of ring pessary. Only $37.5 \%$ who were treated against uterine prolapse were fully satisfied with their treatment. Uterine prolapse was observed highly among large numbers of women having teenage pregnancy, lower educational level, increasing age and high parity women. The perceived service satisfaction was reported to be low among respondents. Limiting frequency of pregnancies, encouraging for teenage pregnancy, health education of pregnancy and postnatal care and provision of educational opportunities are recommended for the prevention of uterine prolapse.
\end{abstract}

Key words: Prevalence, Uterine Prolapse, Associated factors, Ring pessary, Teenage pregnancy

Correcsonding auther: AmupamaTamrakar, School of Health and Allied Sciences, Pokhara University, Lekhnath, Kaski, Nepal.Email: anutamrakar@yahoo.com

\section{INTRODUCTION}

Reproductive mortality and morbidity are one of the major problems for Nepali women, the full extent of which is not exactly known, until recently. ${ }^{1}$ Pelvic organ prolapse is a very common condition, particularly among adult and old women. It is estimated that half of women who have children experience some form of prolapse in later life, but many women don't seek help. So, the actual number of women affected by prolapse is unknown. Even though prolapse is not considered a life threatening condition; it may cause a great deal of discomfort and distress. ${ }^{2}$ The global prevalence of genital prolapse is estimated to be $2-20 \%$ in women under age 45 years. ${ }^{3}$ It is one of the commonest reproductive morbidity in developing country with its very high prevalence among women. ${ }^{4}$

One of the Pelvic organ prolapse is uterine prolapse.Uterine prolapse is defined as falling of the womb, when the muscles of the pelvis are strained to a point where they can no longer support the positioning of the uterus. The uterus drops from its normal position in the pelvic cavity, descending into and eventually, in extreme stages, out of the vagina. ${ }^{5}$

Women comprise slightly over $50 \%$ of total population of Nepal, but the country has one of highest indices of son preference in the world. The consequences of this system can be seen in social indicators such as literacy, child mortality, maternal mortality and morbidity amongst women. ${ }^{6}$ Among the health problems faced by women related to reproductive health, uterine prolapse is a complex condition that is often kept in secret because of the shame of the condition affecting a sensitive part of the woman's body.

In Nepal more than one million women suffer from uterine prolapse, and the majorities of these patients are of reproductive age. ${ }^{6}$ The extent of utero-vaginal prolapse (UVP) is very common among Nepalese women and the incidence rises in elderly. In Nepal, genital prolapse appears to be widespread, but little published evidence exists to buttress this claim. 3 Bonetti et al. in 2002 examined 2,072 women in West Nepal and detected that one in four of these women had genital prolapse. The most commonly perceived cause of prolapse is lifting heavy loads, including in the postpartum period. Most reports describe heavy household and farm working during pregnancy, as well as pre and postdelivery, as the main causes and risk factors. ${ }^{1}$ The clinicbased study conducted among 2,072 women who presented with gynaecological complaints and received a diagnosis in western Nepal, one in four of them had genital prolapse, of whom $95 \%$ had self-reported the prolapse. ${ }^{2}$ This problem exists throughout Nepal and drastically affects women's quality of life. ${ }^{6}$ A study from west Nepal revealed that $40 \%$ of women with uterine prolapse are of reproductive age having given birth to their first child and the extent of problem is more 
among women of disadvantaged and marginalized women. ${ }^{2}$ Similarly, of 50 women attending in family planning clinic, $14 \%$ of them were diagnosed with uterus prolapsed in Doti district and $29.45 \%$ of the 274 women admitted in maternity hospital have self reported pelvic organ prolapse. ${ }^{1}$

Uterine Prolapse is widespread across the country and has affected women in the mountains, hills, plains and the valleys of Nepal. In addition to this, increasing age, adolescent pregnancy and increasing number of pregnancy have greater risk for this condition. So, this problem has been one of the issues of concern for all women, civil society and the government itself.

\section{METHODS}

This was the community based cross-sectional descriptive study performed among the 300 women of the Kaski district who have experienced at least one time pregnancy during her life. Multi-stage sampling technique was adopted in which first stage involved random selection of one electoral constituency; second stage involved random selection of $50 \%$ of the village development committee (three villages) in the selected electoral constituency and the third stage involved purposive sampling to select 300 married women of reproductive aged group from the selected villages (100 samples from each villages). Face to face interview was conducted with respondents using pre-tested, semi structured interview schedule.

Before the collection of data, permission was obtained from the respective authority of VDCs and the respondents. The enumerators were trained for the data collection prior to the data collection. The objectives of the study were explained to respondents before data collection. Data were analyzed by statistical package for Social Sciences (16 Version) and results were presented in table and figures.

\section{RESULTS}

The findings of the study revealed that the mean age of the respondents was 38.83 years. Majority of the respondents $(30.7 \%)$ were of age between 21 to 30 years and only $3.3 \%$ were of below 20 years. Majority of the respondents were Brahmins having $39 \%$ of the total respondents followed by Dalits with $21.7 \%$. Large numbers of the respondents were literate $(74.7 \%)$. Maximum respondents' educational level was primary level (49\%) and the least with bachelor's degree. Half of the respondents were indulged in agriculture and quarters of them were housewives. The major source of more than half $(51 \%)$ of the respondents was agriculture and $52.3 \%$ were living in joint families.

Most of the women $(88.7 \%)$ have heard about the uterine prolapse and the majority of them have heard about uterine prolapsed from radio, followed by from friends and health personnel respectively.

The study illustrated that majority of the respondents (82.3\%) married at the age of below 20 years. The minimum age at marriage was 13 years and the maximum age was 37 years.
More than half $(61 \%)$ had delivered their first child before 20 years of their age. The detail age at first child birth and the number of children is given in table 1 and 2 respectively.

Table 1: Distribution of Respondents by Age at First Child Birth

\begin{tabular}{|c|c|c|c|c|}
\hline Age groups & Frequency & Percent & Mean & Std. Deviation \\
\hline Below 20 & 183 & 61.0 & & \\
\cline { 1 - 3 } $21-25$ & 109 & 36.3 & & \\
\cline { 1 - 3 } $26-30$ & 5 & 1.7 & \multirow{2}{*}{20.17} & \multirow{2}{*}{3.146} \\
\hline $31-35$ & 1 & 0.3 & & \\
\hline Above 35 & 2 & 0.7 & & \\
\hline Total & 300 & 100.0 & & \\
\hline
\end{tabular}

Table 2: Number of Living Children of Respondents

\begin{tabular}{|l|c|c|}
\hline Number of Children & Frequency & Percent \\
\hline One & 54 & 18.0 \\
\hline Two & 89 & 29.7 \\
\hline Three & 70 & 23.3 \\
\hline Four & 47 & 15.7 \\
\hline Five & 20 & 6.7 \\
\hline More than five & 20 & 6.7 \\
\hline Total & 300 & 100.0 \\
\hline
\end{tabular}

Prevalence of uterine prolapse was reported to be $11.7 \%$. Median duration of suffering was two years. Majorities of the respondents were over 30 year's age. Feeling of something coming down was reported by more than $42 \%$ cases followed by vaginal bleeding by more than $37 \%$ as major symptoms. Age of respondents, level of education, income, occupation, age at first child birth, numbers of children, place of first and third delivery, time to resume work after delivery, assistance in first delivery and present and past smoking were significantly associated with uterine prolapse. The strongest variation was observed in age of respondents, age at first child birth and smoking in the past and present.

More than $50 \%$ had received treatment of uterine prolapse and most of them received services from hospitals followed by private medicals. More than $72 \%$ were treated by the application of ring pessary. Only $37.5 \%$ who were treated against uterine prolapse were fully satisfied with their treatment.

\section{DISCUSSION}

Reproductive ill health holds major global burden of diseases for women. It is remarkable that pelvic organ prolapse contribute extremely to lead poor reproductive health.

Prevalence of uterine prolapse was reported to be $11.7 \%$. This result displays small quantity of prevalence of uterine prolapse. Deuwa et al., and Bonetti et al also reported the prevalence of uterine prolapsed as $33 \%$ and $37 \%$ in western districts of Nepal respectively while Dangal estimated the prevalence of pelvic organ prolapsed as $20.1 \%$ in eastern Nepal. ${ }^{7,8,9}$ 
The result in this study demonstrated that $40 \%$ of the women were suffering from uterine prolapse since less than five years with equal numbers even since less than six years indicating that the incidence of cases were not reduced yet. Contradict to this, a study conducted by Bonetti et al., calculated the average time elapsed was 10 years in a campaign based study whereas Barbara Bodner-Adler et al., reported that the median time period for clinical presentation of uterine prolapse was 50 years among those who were attended for the treatment in hospital..$^{2,10}$

Those who had been suffering from the uterine prolapse, most of the respondents $(42.85 \%)$ dictated feeling of something coming down through vagina followed by $34.28 \%$ experienced vaginal bleeding and protrusion from vagina. The findings are supported by the study conducted by Paneru which also reported similar symptoms. ${ }^{11}$

The findings displayed that there is a strong association between age of the respondents, age at first child birth and number of children with uterine prolapse. This finding of the study coincides with the study conducted by Paneru which flaunted significant level of association with the age of respondents, the age at first child birth and number of parity; indicating that the above mentioned factors are the risk factors of uterineprolapse. ${ }^{11}$

The result exhibited that most of the affected population were Brahmins (42/85\%). The level of education, economical status and occupation of the women are significantly related with uterine prolapse. This result was contradicted to the findings of a study conducted by Pant and Deuwa. They stated that majorities of the prolapse cases (45.54\%) were from Dalit. This illustrates that race and caste does not matter as risk factors and even the higher caste women are suffered from uterine prolapse..$^{12,8}$ Paneru also reported that the prevalence of uterine prolapse was higher among those who have low socioeconomic status, illiteracy and women carrying heavy loads or strenuously working. ${ }^{11}$

The findings of this study revealed no significant degree of association with the types of delivery whereas, Marattha revealed that most $(70 \%)$ of the genital prolapse cases developed due to the deliveries conducted at home without the help of birth assistant. ${ }^{13}$

Time of resuming work within 42 days of deliveryand past and present smoking habit were strongly associated with the onset of uterine prolapse. Pant observed that those who were diagnosed having utero vaginal prolapse resumed to work soon following delivery. Similarly, Barbara Bonder reported that most of the uterine patients were smokers. ${ }^{10}$

Majorities of the respondents (87\%) visited public health facilities for the health services during reproductive illness. Nearly fifty percent suffering from uterine prolapse received treatment for uterus prolapsed from hospitals by applying ring pessary $(72.2 \%)$. Kumari found that $57 \%$ patients having uterine prolapse had not taken any services. About $44 \%$ women who were treated by any kinds of services reported that they had significant improvement due to treatment. ${ }^{14}$

Almost all respondents replied that uterine prolapse can be prevented by avoiding lifting or carrying heavy loads. Most of the aforementioned ideas are seen as consistent with the established principles. The findings of the study are supported by Paneru study, resulting that almost all respondents replied that uterine prolapse can be prevented by avoiding lifting or carrying heavy loads followed by intake of nutritious diet. ${ }^{11}$

\section{CONCLUSION}

The study depicted that prevalence of uterine prolapse was estimated to be $11.7 \%$ with higher burden among those with low economic background, over age 35 years, farmers and housewives. The median time of suffering was of prolapse two years. The age of the respondents, monthly income, occupation, age at first child birth, numbers of children, place of delivery, work load during peurperium, time to resume work after delivery, assist in first delivery and smoking have independent significant contribution. Nearly fifty percent suffering from uterine prolapse received treatment for uterus prolapse. Maximum of them received services from hospitals and most of them were treated by applying ring pessary. Less than fifty percent of the women who were treated by any kinds of services reported that they had significant improvement due to treatment while most of the respondents were moderately satisfied with the treatment.

\section{ACKNOLEDGEMENT}

I feel deeply obligated to Mr: Iswar Chand Baniya, Dean, Faculty of Science and Technology, Pokhara University, Mr. Naveen Shrestha, Professor; Central Institute of Science and Technology, Kathmandu and Professor Dr: Bishnu Raj Tiwari for their valuable suggestions, guidance and inputs throughout this study. I gratefully acknowledge enumerators for needful help in data collection and their co-operation despite various difficulties. I extend my sincere thanks to Chairman of all the VDCs and respondents for their co-operation during the study without whose help it would have been impossible to complete my research study.

\section{REFERENCES}

1. CBS. 2002. Population Census. National Report. Central Bureau of Statistics, Government of Nepal 2001.

2. Bonetti TR, Erpelding A, Pathak LR. GTZ/MOHP/UNFPA: Reproductive Morbidity: A neglected issue? Report of a clinic-based study in Far-Western Nepal. Kathmandu 2002. 
3. Thapa SB. Uterine Prolapse: Prevalent among Nepalese women who were deprived of general health services. Booklet on Uterine Prolapse; received through SancharikaSamuha Nepal, The Kathmandu Post 2007; 05-08.

4. Center for Agro-Ecology and Development, Nepal. Uterine Prolapse Study Report 2007.

5. Dutta DC. A Text Book of Obstetrics. Calcutta (India): New Central Book Agency (P) Ltd, 3rd Edition 2005.

6. Shirish ND. A Mannual of Obstetrics. 2nd edition, 2002 ISBN-818147013.

7. Bonetti TR, Erpelding A, Pathak LR. Listening to "felt needs": investigating genital prolapse in western Nepal. Health Sector Support Programme, German Agency for Technical Cooperation (GTZ), Nepal. Reproductive Health Matters 2004 May; 12(23):166-75.

8. Darshan A. Prevalence of Uterine Prolapse amongst Gynecology OPD Patients in Tribhuvan University Teaching Hospital in Nepal and its Socio-Cultural Determinants. Kuala Lumpur, Malaysia: The Asian-Pacific Resource \& Research Centre for Women (ARROW) 2009.

9. Dangal G. A study of reproductive morbidity of women in the Eastern Terai Region of Nepal. Nepal Journal of Obstetrics and Gynaecology 2009; 3(1):32-56.

10. Barbara BA, Shrivastava C, Bodner K. Risk factors for uterine prolapse in Nepal., Int Urogynecol J. 2007; 18:1343-1346.

11. Paneru D. Research report-Uterine Prolapse in Doti District of Nepal. Nepal Health Research Council 2010.

12. Pant PR. Utero-Vaginal Prolapse in Far western region of Nepal. Department of Obstetrics and Gynecology, Institute of Medicine. Journal of Institute of Medicine 2009; 31(2):19-21.

13. Marahatta RK, Shah A. Genital prolapse in women of Bhaktapur, Nepal. Nepal Med Coll J. 2003 June; 5(1):31-33.

14. Kumari S, Walia I, Singh A. Self reported Uterine Proplase in a resettlement colony of North India, Journal of Midwifery Womens Health 2000 July-August; (4): 343- 50. 